\title{
Conciencia feminista, discurso literario y legitimación auctorial: Le Livre de la Cité des Dames de Christine de Pizan
}

\author{
Nieves IBEAS VUELTA \\ Universidad de Zaragoza \\ nibeas@unizar.es \\ ORCID: 0000-0001-8630-4467
}

\section{Resumen}

Cinco siglos después de la edición de sus obras, Christine de Pizan continúa interpelando con su modernidad y transgresión. A esta autora, cuya cultura y saber fueron reconocidos por sus contemporáneos, le debemos la entrada gloriosa de la conciencia femenina en la escritura europea en un contexto condicionado por profunda tradición de hostilidades hacia el sexo femenino. Para ello utilizó de una forma magistral una técnica basada, por una parte, en la utilización de un sujeto enunciativo sexuado en femenino y por otra, en hábiles estrategias discursivas que enlazaban todo un universo intertextual e intercultural, lo que contribuyó específicamente a la legitimación de su escritura y a su entrada en la historia literaria.

Palabras clave: Análisis del discurso literario. Mujeres. Escritoras. Feminismo. Género. Sexualidad.

\section{Résumé}

Cinq siècles plus tard, Christine de Pizan continue de nous interpeller avec une œuvre certes moderne et subversive par rapport à son temps. C'est à la lucidité de cette femme de lettres, dont la culture et le savoir ont été reconnus par ses contemporains, que nous devons l'entrée glorieuse de la conscience féminine dans la tradition littéraire en Europe dans un contexte lourd du poids d'une longue tradition d'hostilités contre le sexe féminin. Le choix d'une stratégie discursive fondée sur un sujet énonciateur sexué au féminin et sur des scénographies réussies lui permettra d'entrer dans l'histoire littéraire à travers un jeu intertextuel et interculturel qui renverse des valeurs traditionnelles qui concernent la place des femmes dans le monde.

Mots clé: Analyse du discours littéraire. Femmes. Écrivaines. Féminisme. Genre. Sexualité.

\section{Abstract}

Five centuries later, Christine de Pizan continues to challenge us with a certainly modern and subversive work compared to her time. It is thanks to the lucidity of this woman of letters, whose culture and knowledge have been recognized by her contemporaries, that the

\footnotetext{
* Artículo recibido el 1/02/2020, aceptado el 31/03/2020.
} 
glorious entry of the female consciousness of women writers in Europe was possible, in a context loaded with the weight of a long tradition of hostilities against the female sex. The choice of a discursive strategy based on a female gendered enunciator and on successful scenographies would allow her to enter the literary history, while reversing traditional values that concern women's place in the world through an interesting intertextual and intercultural work.

Key words: Analysis of literary discourse. Women. Women writers. Feminism. Gender. Sexuality.

Et ne me soit imputé a folie, arrogance ou presompcion d'oser, moy femme, reprendre et redarguer aucteur tant soubtil et son oeuvre amenuisier de louange, quant lui, seul homme, osa entreprendre a diffamer et blasmer sans excepcion tout un sexe (Débat: III, [10], 167) ${ }^{1}$.

\section{Introducción}

Mujer y laica, Christine de Pizan fue capaz de adaptar su escritura a las convenciones de la tradición literaria occidental y, al mismo tiempo, mantener una posición intelectual contraria al discurso hegemónico medieval concerniente a los fundamentos de la historia literaria y, en particular, al espacio que en ella se reserva a las producciones culturales de las mujeres.

En su Livre de la Cité des Dames, escrito entre 1404 y 1405, la autora reivindica un espacio propio como "fille d'étude» y como escritora, que es tanto un espacio físico como metafórico. Sin duda es un lugar para el desarrollo personal, pero va más allá de lo individual e implica un sujeto discursivo plural, puesto que el sujeto enunciativo oscila entre el je sexuado («suis née femme») y un nous que integra a numerosas mujeres que la narradora ha conocido y que le han confiado "leurs pensées secrètes et intimes» (Cité: I, 36). Aun remitiendo esencialmente al conjunto de damas que, en el ámbito de relación de la escritora, forman parte de la élite cultural y social de inicios del siglo $\mathrm{XV}$, nous moviliza un innegable sentimiento de sororidad con todas las mujeres y una perspectiva que, salvando las distancias históricas que nos separan, hoy denominaríamos de género.

En este sentido, desde el marco epistemológico reconfigurado por las corrientes de la crítica discursiva feminista, la relectura del hecho normativo que santifica a los escritores y sus obras ha permitido una mejor comprensión de las críticas dirigidas

\footnotetext{
${ }^{1}$ Con el fin de simplificar las referencias a las obras de Christine de Pizan que hemos utilizado, vamos a citarlas en el texto con una palabra clave de su título que remite a cada una de ellas. Así La Cité des Dames aparecerá como Cité; Le livre de l'Advision Cristine, como Advision; Le livre des epistres du debat sus le Rommant de la Rose como Epistres; Le livre du Chemin de Longue étude como Chemin; y Le débat sur Le Roman de la Rose como Débat.
} 
por Christine de Pizan a las autoridades literarias que instauran y transmiten el discurso sobre la inferioridad del sexo femenino, rebatido desde el inicio de la obra: «l'excellence ou l'infériorité des gens ne réside pas dans leur corps selon le sexe» (Cité: I, IX, 55).

La posición enunciativa adoptada en sus textos arroja luz sobre su discurso comprometido y pone de relieve un estilo indisociable del deseo firme de escribirse a sí misma e inscribirse doblemente, como mujer y como mujer de letras. La lectura de su obra está condicionada desde el principio por la presencia del yo sexuado femenino que convierte la obra en un texto sobre-marcado y que activa lo que Christine Planté denomina "la sospecha del género» (1997: 81). Christine de Pizan propone dos soluciones alternativas para que una mujer en su época pueda convertirse en escritora (Cerquiglini-Toulet, 1994: 82-83): "transformarse en hombre», como sucede en el Livre de la Mutation de Fortune, o "hacerse mujer de manera superlativa", que es la opción elegida para la Cité des Dames. El presente trabajo se centra en el análisis de esta segunda posibilidad, explora las estrategias utilizadas por una escritora para la que experiencias y vivencias "sono parte integrante ed imprescindibile di tutta l'aventura' nel campo delle lettere» (Soleti, 2015: 84), y tiene en cuenta el diálogo intertextual e intercultural con textos y relatos anteriores (clásicos y religiosos) y con su propia producción literaria anterior ${ }^{2}$, en la que hay una presencia privilegiada de lo femenino. Desde este ángulo, el Livre de la Cité des Dames aborda la reevaluación de los textos misóginos existentes (Ibeas Vuelta, 1990) y elabora un entramado discursivo de gran complejidad en el que la construcción del relato, la edificación de la Ciudad de las Damas, la fundamentación de su legitimidad como escritora y el paso a la posteridad de su obra literaria representan un mismo objetivo.

\section{Una escenografía para la legitimación de la propia escritura: la anunciación entre libros}

La posición discursiva de Christine de Pizan es significativa en el panorama intelectual medieval que comparte con sus contemporáneos, frente al papel que estos desempeñan en el proceso de legitimación de su escritura, y también en relación con sus lectoras y lectores presentes y futuros. Su posición revela, por una parte, el compromiso moral de una escritura profundamente anclada en la idea de una construcción de la feminidad a través del conocimiento; por otra, la elección poética y artística de un proyecto literario llevado a cabo con éxito, que conlleva la fabricación de un ethos de autora para garantizar su credibilidad (Amossy, 2010) y la identidad auctorial en todos sus textos, y en particular en La Cité des Dames.

A partir de los siglos XII y XIII se produce un fenómeno que favorecería sin duda la escritura de Christine de Pizan; se trata, en palabras de Jacques Le Goff

\footnotetext{
${ }^{2}$ Para la definición de los conceptos de genericidad y diálogo intertextual como principios de análisis véase Ute Heidmann (2011) y su aplicación al análisis comparativo de los cuentos.
} 
(1996: 508), del «essor de l'autobiographie, de l'intériorisation de la vie morale». $L a$ Cité des Dames nace tras un siglo XIV caracterizado por un discurso invadido por las circunstancias y por la profusión de escrituras en primera persona en las que yo, escasamente narrativo, tiende a confundirse con la persona del autor (Zumthor, 1975: 179). Si bien La Cité des Dames no es presentada como una autobiografía, es cierto que incorpora elementos autobiográficos reconocidos por la propia autora. Su recepción, como ha ocurrido con otras obras de carácter autobiográfico escritas por mujeres, ha resultado más compleja y diferente que en el caso de las autobiografías masculinas, por el hecho de proceder de una pluma femenina, como explica Jude Long en su interesante estudio Telling Women's Lives (1999). En medio de los graves problemas de transmisión y visibilidad para las obras escritas por mujeres, Christine de Pizan, que busca pautas de decibilidad (Rivera-Garretas, 1994: 33) de su experiencia y de su pensamiento para su discurso de autoridad, utiliza la primera persona narrativa como estrategia de auto-legitimación de su escritura, para poder nombrar el mundo.

La coincidencia del nombre de la protagonista-narradora con el de la autora, las referencias familiares o la evocación de la propia experiencia como mujer y como escritora (Blumenfeld-Kosinski, 2001: 17) favorecen la identificación de autora y narradora. Por una parte, la coexistencia de un yo-Christine-autora y un yo-Christinepersonaje genera fructíferas ambigüedades enunciativas para canalizar discursos transgresores. Por otra, existe un efecto pseudo-autobiográfico que induce a interpretar la obra como «the textual performance of the supposed lived life» de Christine de Pizan a la que alude Laurence de Looze (1997: 154). Esta estrategia enunciativa y narrativa, que la autora llevaba poniendo en práctica ya desde hacía una década (Brownlee, 2000: 19-20), acabará convirtiéndose en uno de los rasgos más característicos de su estilo.

Christine de Pizan moviliza una extensa red de representaciones colectivas sobre las mujeres que intervienen en la composición del retrato de la protagonista. Todas las que aparecen mencionadas a lo largo de la obra tienen algo en común: han caído en el olvido o son víctimas de los malentendidos o del error de la Historia. Al igual que en otros casos de autobiografías femeninas y a diferencia de las masculinas, "women represent themselves as connected", como apunta Jane Long (1999: 56). Christine de Pizan recurre a estas figuras femeninas para refutar y desmentir muchos de los discursos contra las mujeres y contra lo femenino que se han consolidado en estereotipos. Desmonta poco a poco tales representaciones gracias a la intervención de tres Damas coronadas y de gran dignidad (Cité: I, II, 38) que, al inicio del relato, llegan del Cielo para consolar a la protagonista del abatimiento en el que se encuentra sumida tras la lectura de tantos ataques virulentos contra las mujeres. Su misión es extraordinaria: ayudar a Christine a construir y fortificar la "Ciudad de las Damas», una urbe eterna y sin parangón que albergará a las mujeres ilustres (Cité: I, III, 42) y a las virtuosas, de una belleza sin igual (Cité: I, IV, 43). La voluntad que muestra la 
escritora transgrede las leyes de la norma patriarcal que regulan el valor de las obras literarias, puesto que con la palabra de Christine y la de las tres Damas elabora un discurso crítico contra los juicios misóginos de algunos textos que gozan de gran reconocimiento en su época. A la visión del mundo que traslada la sociedad en la que se inscribe, la autora contrapone otra, bien diferente, en la que las mujeres sí tienen cabida con pleno reconocimiento de sus posibilidades y de su valía.

Tanto la escenografía que utiliza la Christine de Pizan, como su opción narrativa o la extensa galería de retratos femeninos que transitan por La Cité resultan indisociables de las condiciones de enunciación del texto (Maingueneau, 2004: 34-35). La autora, que aspira al éxito de su obra y a su gloria como escritora, se destaca y se posiciona como mujer culta y escritora, operando reajustes en su ethos de escritora. Sale al paso así del imaginario sociodiscursivo medieval sobre las mujeres de letras y, por tanto, de su ethos previo que, sin duda, condicionaba la lectura de sus obras. La posición del locutor es determinante para cimentar el grado de autoridad que el público está dispuesto a reconocerle (Amossy, 2010: 73), y Christine de Pizan aprovecha las técnicas y los códigos culturales, literarios e históricos que comparte con otros escritores coetáneos, religiosos o no, para activar toda una serie de «escenas literarias» que son esenciales para su necesaria legitimación. La autora realiza un reajuste de su ethos preconstruido de mujer de letras, lo orienta hacia la captación de la benevolentia de su público, y construye una posición dialógica alternativa a la historia literaria y a la cultural hostil a las mujeres, desde un anclaje social, intelectual y artístico propio. Una obra anterior, la Epistre au Dieu d'Amour, avanzaba ya en este sentido toda una declaración de principios:

Car, entre moy et ma dame Nature,

Ne souffrerons, tant corn le monde dure,

Que cheries et amees ne soient

Maugré touz ceulz qui blasmer les vouldroient,

Et qu'a pluseurs meismes qui plus les blasment

N'ostent les cuers, et ravissent et emblent (vv. 297-302).

En el marco de una tradición literaria fuertemente misógina, el análisis del régimen de la mediación (lugar de enraizamiento y de enunciación) utilizada por Christine de Pizan muestra la preeminencia de lo simbólico para nombrar la realidad sexual en femenino (Rivera-Garretas, 1994: 197). La mediación constituye un eficaz recurso a la autoridad también simbólica de escenas-texto culturales preexistentes que importa del imaginario intelectual (como es el caso del étude, espacio de recogimiento investido de autoridad patriarcal) y de relatos-textos del universo religioso (como la Anunciación), y confiere el máximo protagonismo a personajes femeninos. Desde este punto de vista, nos interesan especialmente los elementos que forman parte de la escenografía de la obra, entendida como escena narrativa construida por el texto y que, a su vez, tiene la virtud de legitimar el propio texto que la engendra, en un movi- 
miento circular en el que es «à la fois condition et produit de l'œuvre» (Maingueneau, 2004: 192).

\subsection{El estudio cristiniano: una habitación apropiada}

El íncipit de la Cité des Dames procura una primera imagen de la protagonista dentro de una escena fundamental y fundadora: Christine, mujer sin vínculos matrimoniales, solitaria, laica, entregada a la meditación y al estudio, aparece rodeada por un conjunto de libros en un espacio de recuerdo y de saber. Esta construcción intertextual, que remite a escritos-textos anteriores, contribuye a dar consistencia a la paratopía de la autora: ${ }^{3}$

Selon mon habitude et la discipline qui règle le cours de ma vie, c'est-à-dire l'étude inlassable des arts libéraux, j'étais un jour assise dans mon étude, tout entourée de livres traitant des sujets les plus divers. L'esprit un peu las de m'être si longtemps appliquée à retenir la science de tant d'auteurs (Cité: I, 35).

La escena de apropiación de lo masculino (en este caso, el étude) por parte de una mujer es inusual en el imaginario medieval. En Le Livre de la Cité des Dames, el estudio-biblioteca representa un lugar de acceso femenino al conocimiento, a la ciencia y a la creación de opinión sobre asuntos que no solo conciernen a las mujeres. De este modo, un espacio tradicionalmente masculino se transforma en un espacio femenino de autoridad y de legitimidad ${ }^{4}$. La dimensión alegórica del cuarto de estudio encarna la notoria inclinación de la autora-narradora al estudio incansable de las artes liberales (Cité: I, I, 35) y a la búsqueda de la verdad (Cité: I, III, 41). El hecho de mostrar esta escena como posible la hace posible en el contexto del pacto discursivo que Christine de Pizan propone a su público. Sus lectoras y lectores reciben así la invitación para una cooperación ineludible (Eco, 1979) que les hará cómplices de la cuestión fundamental y problemática que atraviesa los textos de la autora, es decir, la legitimación de las producciones culturales de las mujeres y la lucha contra las barreras que impiden que mujeres y obras de mujeres puedan ser referencia de autoridad: «C'était une fontaine qui sourdait; un grand nombre d'auteurs me montaient en mémoire. Je les passais en revue les uns après les autres» (Cité: I, I, 37).

Esta apropiación en femenino prepara el terreno para la denuncia de la segregación sexual y del desigual reparto de poder entre los sexos (Bard, 2004), a partir de una escena que remite a otro texto-escena anteriormente utilizado por la autora en $L e$ Chemin de Long Estude:

Un jour de joye remise

Je m'estoie a par moy mise

En une estude petite,

\footnotetext{
${ }^{3}$ Utilizamos el concepto de paratopía en los términos definidos por Maingueneau (2004: 124).

${ }^{4}$ Véase a este respecto una revisión reciente realizada por Cristian Bratu (2019: 283 y ss.) de las fuentes que pudieron servir de inspiración a Christine de Pizan para la redacción de sus obras.
} 
Ou souvent je me delite

A regarder escriptures

De diverses aventures (vv.171-176).

En este sentido, el estudio de la Cité, centro neurálgico de la obra, se convierte en un espacio básicamente femenino; no solo pertenece a una mujer, sino que solo las mujeres lo visitan: Christine, heroína de la historia, su madre (metáfora de una profunda conexión entre las mujeres), las tres Damas y una amplia congregación de mujeres -históricas o ficticias- que construyen una red de filiaciones simbólicas dimanantes, sobre todo, de la tradición cristiana y de la mitología greco-latina.

El imaginario de los escritos y de los libros ocupa un lugar importante en la obra de Christine de Pizan ${ }^{5}$ y es crucial en la escenografía du Livre de la Cité. La construcción de la Ciudad comienza en el Campo de las Letras, ese "pays riche et fertile [...] où l'on trouve tant de fruits et de douces rivières, là où la terre abonde en toutes bonnes choses» (Cité: I, VIII, 48). En la escena inaugural, la autora se representa a sí misma con un libro en la mano que actúa de «embrayeur narratif» en un juego intertextual (Cerquiglini, 1993: 77) enmarcado en un locus amoenus intelectual y literario que enlaza con los temas tradicionales del diálogo consigo mismo (Delormas, 2015: 183) y la constante búsqueda "du vrai» de Christine, "qui [l']a retirée du monde et rendu ainsi solitaire» (Cité: I, III, 41-42). La actitud de la protagonista, la expresión de su recogimiento, de su tristeza por los ataques contra las mujeres, de sus dudas sobre la veracidad de tales opiniones, así como el ambiente de penumbra del estudio, propician la luminosa visión-aparición de tres damas que la acompañarán hasta el final del relato: Razón, Rectitud y Justicia. Con ellas entabla Christine la larga conversación que remite al nexo intertextual de la escena de la visita de Dama Filosofía a Boecio en Consolatio philosophiae.

\subsection{De la Anunciación de María a la Anunciación de Christine}

La aparición de las tres figuras alegóricas (personificadas en tres DamasVirtudes: Razón, Rectitud y Justicia) en el espacio simbólico de conocimiento y contemplación, en el instante en el que Christine se está lamentado ante Dios por haber

\footnotetext{
${ }^{5}$ El panorama expuesto por los historiadores sobre las bibliotecas en la Edad Media y sobre la homogeneidad del conocimiento cultural durante este período, permite a Jacques Verger (1998: 86-89) afirmar que "partout on retrouve les mêmes tendances et pratiquement les mêmes livres». Verger (1998: 141) cita a Christine de Pizan, dado que forma parte del grupo de esos autores casi profesionales a los que alude en su obra, «une de ces rares femmes assez averties au Moyen Âge des disciplines savantes pour qu'on puisse l'associer au groupe des gens de savoir», pero no utiliza categorías de análisis histórico que le hubieran permitido obtener resultados relativos a las circunstancias del acceso al saber de las mujeres. Los trabajos históricos sobre los intelectuales o las gentes de saber en la Edad Media suelen excluir a las mujeres. La ausencia del Livre de la Cité des Dames, o del Chemin de Long Étude en el listado de títulos que conforman el índice de las obras clásicas y medievales realizado por Jacques Paul (1998), que únicamente menciona el Livre des faits et bonnes moeurs du sage roi Charles Quint, ilustra tal ocultación.
} 
nacido en un cuerpo femenino que es objeto de vituperios, conlleva una anunciación. Dama Razón trasmite a Christine la encomienda de defender a las mujeres frente a los discursos misóginos medievales, con el fin de crear una Ciudad para «chasser du monde cette erreur» y lograr que "les dames et autres femmes méritantes puissent désormais avoir leur place forte où se retirer et se défendre contre de si nombreux agresseurs» (Cité: I, III, 42). El texto de esta escena conecta con el intertexto evangélico de la Anunciación del ángel Gabriel designado por Dios para comunicar a María que se iba a convertir en la madre del Mesías (Caraffi, 1998), y con la rica tradición iconografía que dicho episodio generó:

Y entrando le dijo: «Alégrate, llena de gracia, el Señor está contigo.» Ella se conturbó por estas palabras, y discurría que podría significar aquel saludo. El ángel le dijo: «No temas, María, porque has hallado gracia delante de Dios» (Lucas, 1, v. 2630).

[j]e vis soudain descendre sur mon giron un rayon de lumière, comme si le soleil était venu en ces lieux. Mais mon cabinet étant obscur, et le soleil ne pouvant y entrer à cette heure, je m'éveillai en surtaut, comme d'un profond sommeil. Levant la tête pour regarder d'où venait cette lumière, je vis se dresser devant mois trois dames couronnées, de très haute dignité [...]. Alors la première des trois dames me sourit et s'adressa à moi en ces termes: "Ma chère enfant, ne crains rien, nous ne sommes point venues ici pour te nuire ou te porter préjudice, mais plutôt pour te consoler " (Cité: I, II, 38).

Aunque los términos del contenido del anuncio son obviamente diferentes, el alcance de la inmensa responsabilidad atribuida a Christine recuerda el precedente bíblico de la dimensión colosal de la profecía del ángel:

No temas, María, porque has hallado gracia delante de Dios; vas a concebir en el seno y vas a dar a luz un hijo, a quien pondrás por nombre Jesús. Él será grande y será llamado Hijo del Altísimo, y el Señor Dios le dará el trono de David, su padre (Lucas, 1, v. 30-32).

[t]u dois savoir que [notre venue] c'est pour chasser du monde cette erreur dans laquelle tu étais tombée, afin que les dames et autres femmes méritantes puissent désormais avoir une place forte où se retirer et se défendre contre de si nombreux agresseurs. [...] et c'est pour cela que tu nous vois ici toutes trois. Nous t'avons prise en pitié et venons t'annoncer la construction d'una Cité; c'est toi qui as été choisie pour construire et fermer, avec notre aide et conseil, cette citadelle hautement fortifiée (Cité: I, III, 42). 
Christine de Pizan revisa la tradición literaria y pone en escena una trinidad de peso $^{6}$ conformada por Raison, Droiture y Justice, al tiempo que instituye una sacralidad, también simbólica, que abre la puerta al discurso de defensa de las mujeres mediante una palabra profética laica que viene autorizada por la encomienda divina (Cité: I, III, 41). Como recuerda Bernard Ribémont (2014: 153-154), no es la primera vez que esta tríada aparece en escena; ya en el siglo XII está presente en el Policraticus de Jean de Salisbury, pero en el caso de La Cité, la novedad consiste en la alegorización que utiliza la autora para mostrar agrupadas a estas tres figuras.

La misión que Christine-personaje recibe de boca de las Damas concuerda con el proceder de Christine-escritora y mujer de letras, muy crítica con los detractores de su sexo, tanto en su obra como en sus escritos personales. Los trabajos para asentar los cimientos de la nueva Ciudad consisten en la formulación retórica de una larga serie de preguntas de Christine, a las que volveremos más adelante, acerca de la opinión generalizada de tantos varones sobre la supuesta «incapacidad intelectual» de las mujeres, que les impide acceder a las ciencias más elevadas. Las palabras de Dama Razón al personaje le hacen ver su ingenuidad y su error en la interpretación de los hechos; le aportan seguridad en sí misma como mujer y como pensadora, al igual que la lucidez necesaria para contemplar el mundo de otra manera ( $R$ Reviens donc à toi, reprend tes esprits et ne t’inquiète plus pour de telles billevesées», Cité: I, II, 40) y para decirlo con ojos y palabras de mujer. La conversación con Dama Razón legitima la palabra de Christine-personaje-autora gracias de nuevo al recurso a una mediación de autoridad femenina incuestionable, pues la dama ha sido enviada por Dios. Christine acaba comprendiendo la falsedad de los agravios misóginos y compartiendo la opinión de las Damas: «Car vous m'avez déjà fait comprendre qu'ils [les hommes qui blament les moeurs des femmes] ont tort» (Cité: I, VIII, 48).

La estrategia de la primera persona narrativa favorece igualmente la asociación del je-Christine con la figura de María y proporciona pilares sólidos para una escenografía que contiene las condiciones discursivas adecuadas al objetivo trazado: poner en valor lo femenino y a su sexo. El decir es un elemento de primer orden en la constitución de la escenografía como escena de palabras: las de Christine-narradora, las de las Damas y en particular las de Christine-personaje cuando asume el encargo encomendado. En este último caso, Christine dice y se muestra siguiendo el modelo de María durante el episodio de la Anunciación, en un relato que recurre a una mediación femenina mixta, religiosa y profana. La presencia femenina laica, conformada por esas tres figuras femeninas alegóricas, es incorporada a una escena religiosa, conocida y reconocible en torno a la María de los textos bíblicos y evangélicos:

Dijo María: «He aquí la esclava del Señor; hágase en mí según su palabra». Y el ángel dejándola se fue (Lucas 1, v. 37-38).

${ }^{6}$ En un pasaje de su Infierno, también Dante evoca a tres mujeres que le han ayudado (la Virgen María, Beatriz y Lucía), como recuerda Anne Slerca (1995: 221). 
Puis je leur adressai cette supplique: «Oh! Dames de souveraine dignité $[\ldots]$ Voici votre servante prête à vous suivre. Commendez, j'obéirai. Et qu'il soit fait de moi selon vos paroles» (Cité: I, VII, 47).

Christine de Pizan utiliza escenas, imágenes y discursos poderosos para restituir a su sexo, y María representa el referente femenino ideal que, como señalara Nora Catelli (1991: 102), no solo es y dice, sino que es pura potencia. En la parte final del libro, las últimas referencias a María, como «impératrice et princesse» eterna (Cité: III, III, 241), y el paralelismo establecido con la protagonista, funcionan una vez más como recurso legitimador para este universo utópico femenino, considerado como la primera ginecotopía ${ }^{7}$ conocida de la historia: María es la representante femenina de la delegación del poder divino para toda la eternidad en una ciudad ideal habitada únicamente por mujeres, cuya construcción ha sido encomendada por las tres Damas a Christine, siguiendo una arquitectura propiciada por una genealogía femenina inédita.

Si la Anunciación de María es un texto profético de la concepción de Jesús, la escena enunciativa de La Cité des Dames está en el origen de la concepción del libro, un paralelismo que Jacqueline Cerquiglini-Toulet (2006: 293) interpreta como una «homología» entre el útero de la Virgen y la biblioteca de Christine del que nace la Cité des Dames, "lugar y libro» simultáneamente. En este sentido, el anuncio que recibe Christine abre la perspectiva de la escritura del Livre de la Cité des Dames, que realmente está ya en proceso de elaboración: la escritura constituye el acto fundacional de la Ciudad y el relato justifica a su vez el propio libro que lo contiene.

\subsection{Un yo demiúrgico «con ojos de mujen»}

La escritura en primera persona de La Cité se estructura esencialmente en torno a un proceso enunciativo en el que yo (la enunciadora protagonista y enunciadora principal del relato) desempeña un papel fundamental como principio generador de un relato cosmogónico sobre la hermosa Ciudad, nueva y eterna, que es en realidad el relato de un nuevo mundo. Esta decisión narrativa, que confiere verosimilitud a las ficciones (Hubier, 2003: 135), reafirma el discurso de Christine.

La posición de la autora desde el punto de vista social y cultura facilita obviamente la formulación de su proyecto $^{8}$. Christine de Pizan disfrutaba a principios

\footnotetext{
${ }^{7}$ El término ginecotopía fue introducido por Ursula K. Le Guin en la década de los ańos 80, y posteriormente utilizado por Mercè Otero i Vidal en la introducción de su traducción de La Cité des Dames al catalán, en 1990, entre otras.

${ }^{8}$ Christine de Pizan fue una escritora respetada en su tiempo, pero su reputación no fue más allá de un siglo, como explican autoras como Jude Long (1999) y Susan Schibanoff (1983), recogiendo no solo la excepcionalidad que representa tal reconocimiento, por ser mujer, sino también los agravios sufridos, los «redescubrimientos» posteriores de que fue objeto o los obstáculos editoriales que impidieron una impresión más temprana de sus textos escritos en primera persona.
} 
del siglo XV en Francia de una reputación de mujer erudita que Érick Hicks atribuye a su obra lírica (edición de la La Cité, 1977: XLI) y que Margaret Wade Labarge extiende hasta Inglaterra (1986: 235). En su edición crítica del Livre de l'Advision Cristine, Christine Reno y Liliane Dulac (2001: XII) hacen mención a la fama internacional de Pizan cuando en 1405 comienza a escribir la obra y fundamentan esta afirmación en la cantidad de mecenas que se interesaban por sus trabajos tras la publicación de Mutacion de Fortune (1403), la Cité des Dames (1405) et le Livre des trois Vertus (1405). La colaboración conjunta con Jean Gerson incrementó el prestigio de Christine de Pizan como escritora en los círculos académicos y varios contemporáneos suyos no dudaron en reconocerle en vida una autoridad que apreciaron incluso aquellos intelectuales con los que mantuvo diferencias. Es el caso de Maître Gontier Col, quien, en una de sus cartas recogidas en la edición de Andrea Valentini (2014), se dirige de este modo a la "prudent, honnouree et sçavant damoiselle Cristine»:

Femme de hault et eslevé entendement, digne d'onneur et recommandacions grans, j'ay ouy parler par la bouche de plusieurs et nottables clers que, entre tes autres estudes et oeuvres vertueuses moult a louer (Espistres: [II], [6] et [7] p. 152).

Si el espacio y el entorno de la heroína de la Cité des Dames denotan un elevado nivel cultural, la escritura de Christine de Pizan es la prueba clara de su profundo conocimiento de diversas disciplinas, en particular de la producción de libros y la compilación de obras (Bratu, 2019: 322). Su participación activa en la elaboración material de los manuscritos y en su difusión la ha llevado a ser considerada como la primera escritora profesional. En la introducción a su edición crítica del Chemin de Long Estude, Andréa Tarnowski (2000: 11) subraya que los conocimientos de Christine de Pizan en el campo de la edición de libros fue acrecentándose paulatinamente. Así lo demuestran sus transcripciones y anotaciones, al igual que el esmero con el que se ocupó de las ilustraciones, que fue reuniendo en cuidadas recopilaciones para ganarse el favor de influyentes mecenas. En esta historia de compromiso personal y artístico, el amor por la lectura que ella confiesa una y otra vez en sus escritos epistolares - «[...] j'aimme biaux livres et subtilz, et biaux traitiés, et les quiers et les cerche et les lis voulantiers si rudement comme les sache entendre» (Hicks, 1997: 147, v. 1047-1049)- lo traslada a las protagonistas de sus libros, como se muestra no solo en La Cité des Dames, sino también en otras obras como Le Chemin de Long Estude:

Comme il racompte en son traictié

$\mathrm{Ou}$ je leu toute la seree;

Mais se j'eusse eu longue asseree,

L'i eusse, croy, voulu user,

Tant me plaisoit m'i amuser,

Car moult m'estoit belle matiere

Et de moy conforter matiere (104, vv. 284-290). 
Con gran habilidad, Christine de Pizan aprovecha su posición social para llegar a un amplio público desde su experiencia personal como mujer. La atribución de su propio nombre a la protagonista de su libro contribuye a nutrir el ethos que otorga voz al discurso (Maingueneau, 2004: 55), permite a la autora ocupar una posición en el campo literario y le confiere una postura que constituye su «identidad literaria» (Soleti, 2015: 126; Meizoz, 2017: 18-19).

La Cité está concebida según claves culturales de su época que la hace posible y legible, como puede apreciarse en la construcción de la narradora/personaje a través de la cual Christine de Pizan forja una imagen irrefutable de sí misma, asociando su persona con la figura mediadora de María y la Ciudad de Dios, jugando con la similitud entre su nombre, Christine, y el de Cristo, presente ya en poemas anteriores:

Os vous ay dit de mes parens,

Lesquieulx sont assez apparens,

Os vous diray quel est mon nom,

Qui le vouldra savoir ou non,

Combien qu'il soit pou renommé,

Mais, quant pour estre a droit nommé

Le nom du plus parfait homme,

Qui oncques fu, le mien nomme,

I. N. E. faut avec mettre,

Plus n'y affiert autre lettre (Mutacion: vv. 369-378).

Las metarreflexiones sobre el propio proceso de la invención literaria son constantes. También lo son a propósito de la construcción del yo y la técnica dialógi$\mathrm{ca}$, expuesta fundamentalmente en tres niveles: en las conversaciones entre yo y mi misma, yo y las damas; en la evocación de intercambios anteriores con otras mujeres; y entre yo y el público de la obra, sus lectoras y lectores. El proceso de subjetivación enunciativa y el juego epónimo que Christine de Pizan lleva a cabo en varias de sus obras contribuyen a con-fundir la identidad de la instancia narrativa y discursiva para hacerla converger en la figura de la autora: Le Chemin de Long Estude, Le Livre de la Mutacion de Fortune y, muy especialmente, en Le Livre de l'Advision Cristine.

En un periodo histórico y cultural en el que la voz de las mujeres permanece restringida, la libertad es la escritura, el hecho de escribir y hacerlo público, como apunta Mercè Otero Vidal (2004: 197). El ejercicio de esta libertad para configurar una ginecosociedad le permite a la autora desvelar y poner de relieve muchos de los límites que reprimen las posibilidades de actuación de las mujeres. Frente a esos límites, Christine de Pizan utiliza la pluma para plantear en $L a$ Cité una alternativa imaginaria que transgrede los discursos que los sustentan. A este respecto, su voluntad de trasladar su propia experiencia, como mujer y como escritora, reposa de hecho en una estrategia discursiva que configura un nuevo modelo hermenéutico que posee no solo dimensiones literarias sino también filosóficas (Soletti, 2015: 84) y políticas. 


\section{Un anclaje en el interdiscurso y una posición sociodiscursiva a contracorriente}

La voz auctorial problematiza en La Cité las consecuencias nefastas de asociar el «cuerpo» a la «naturaleza femenina», porque tal naturaleza es la que niega a las mujeres la condición de sujeto de la palabra dicha o escrita (Oberhuber, 2013: 5). A contracorriente, Christine de Pizan toma la palabra y escribe en un escenario doblemente condicionado por las reglas de la institución discursiva y por el imaginario social. Su posicionamiento como enunciadora literaria desde el punto de vista del sexo, es decir, su deseo expreso de mostrar el género/sexo de la instancia enunciadora, tiene dos consecuencias importantes: por una parte, la inscribe a ella en el discurso y la hace partícipe del discurso, en el sentido definido por Østenstad (2013: 115); por otra, obliga a su público lector a definirse, a construirse una imagen del yo textual à partir del ethos de autora, en un proceso que es el resultado de un intercambio verbal en el que el yo se presenta necesariamente frente al vosotros/vosotras (Amossy, 2010: 7).

En este sentido, La Cité des Dames construye un imaginario simbólico cuya intertextualidad asegura la legibilidad de la obra (Ibeas Vuelta y Millán Muñío, 1998) y permite a Christine de Pizan tomar posiciones en el universo discursivo vigente, utilizando múltiples referentes para legitimar su escritura, para protegerse frente a cuestionamientos sobre su conocimiento y sobre el valor de su palabra. Así, la autora extrae de De Claris Mulieribus de Boccaccio algunos de los temas más importantes (Slerca, 1995: 221) y los reaprovecha en una nueva situación. Como apunta Lori J. Walters (2018: 279), tanto Boccaccio como Christine de Pizan son conscientes de la utilidad pública de su escritura. Ahora bien, las perspectivas de uno y otra respecto de las mujeres son muy diferentes, y sus estrategias responden a posicionamientos discursivos distintos. De entrada, Boccaccio escribe en latín -lengua de autoridad propia del modelo clerical masculino- y utiliza la tercera persona narrativa que permite borrar las connotaciones sexuales del locutor y conlleva una menor implicación discursiva. Christine de Pizan, escritora laica a quien le ha sido reconocido un papel relevante en el desarrollo de las lenguas vernáculas tras la irrupción de los laicos en el campo político del siglo XV (Blanchard, 1990: 201-202), utiliza la lengua vernácula, y la primera persona gramatical; con ellas programa la construcción de un sujeto sexuado en femenino, acorde con la reescritura de la mitología griega y romana que su obra lleva a cabo en el marco de la tradición cristiana (Hall y Visser, 1997: 31). Christine de Pizan readapta escenas y discursos bíblicos para su proyecto laico, con el fin de persuadir a las mujeres para que «reorienten» en beneficio propio los escritos de acusación que reciben, consejo que le ha transmitido Dama Razón, "verdadera sibila»: "Je te recommande donc de tourner à ton avantage leurs écrits là où ils blâment les femmes, et de les prendre ainsi, quelles que fussent leurs intentions» (Cité: I, II, p. 39). Este consejo abre un extenso espacio intertextual en la obra, que pone en cuestión algunas obras de su tiempo y el renombre de sus autores. 
El pre-texto que da pie a las evaluaciones críticas de Christine es un opúsculo que no le pertenece-Les lamentations de Mathéole-pero que desea leer por tratarse de una obra que tiene fama "de dire grand bien des femmes» (Cité: I, I, p. 35). Pronto comprueba que el libro no contribuye en nada a la edificación moral y a la virtud, y censura la indecencia del lenguaje utilizado y de los temas introducidos (Cité, I, I, 36). Esta pequeña obra, de la que la protagonista ya se había prudentemente desvinculado antes incluso de nombrarla (protegiendo de este modo su ethos) se convierte en símbolo del conjunto de textos ofensivos contra las mujeres y en motor narrativo de la Cité:

Mais la lecture de ce livre, quoiqu'il ne fasse aucunement autorité, me plogea dans une rêverie qui me bouleversa au plus profond de mon être. Je me demandais quelles pouvaient être les causes et les raisons qui poussaient tant d'hommes, clercs et autres, à médire des femmes et à vitupérer leur conduite soit en paroles, soit dans leurs traités et leurs écrits (Cité: I, I, 36).

Christine-personaje-narradora formula entonces una duda retórica sobre la veracidad o falsedad de las palabras misóginas que da pie a profundas reflexiones: ¿Acaso Dios se equivocó al crear a las mujeres?: "Car, comment serait-il possible que tu [Dieu] te sois jamais trompé?» (Cité, I, I, p. 37). ¿Debe fiarse del análisis de su propia conducta y de la de las mujeres que le han dado a conocer sus pensamientos (Cité: I, I, 36)? O, por el contrario, ¿debe seguir las tesis que sustentan los textos misóginos escritos por autores que gozan de tanta relevancia? La mera formulación de estos dilemas produce el desplazamiento de las «lamentaciones de Mathéole» a las «lamentaciones de Christine», gracias a un discurso igualmente retórico de consolación que se origina súbitamente con la visión de las tres Damas y las secuencias dialogadas que conforman la base estructural del relato alegórico.

Tampoco era la primera vez que Christine de Pizan echaba mano de este tipo de pretextos: en Le Livre du Chemin de Long Estude había ya presentado los efectos, esta vez beneficiosos, que la lectura casual de De consolatione de Boecio le había producido cuando se encontraba en un estado de desolación.

Et lors me vint entre mains

Un livre que moult amay,

Car il m'osta hors d'esmay

Et de desolacion:

Ce ert De Consolacion

Böece, le prouffitable

Livre qui tant est notable (98-100, vv. 202-208).

En general, todas las argumentaciones de Christine de Pizan parten de saberes y textos anteriores que constituyen una referencia de autoridad y cuya legitimidad quedará convenientemente valorada en la Cité des Dames; la autora contribuye así a 
engrosar conscientemente el denominado archivo histórico del saber de las mujeres según Margaret Zimmermann (1999: 88). En la mayoría de los casos, sus críticas alcanzan a numerosos y prestigiosos autores latinos detractores de las mujeres, como es el caso de Ovidio, a quien rechaza por los planteamientos misóginos de su Ars amandi o de sus Remedia amoris, (Cité: I, IX, 52); a Cecco de Ascoli (Francesco Stabili), que tenía a todas las mujeres «en abomination, haine et dégoût» (Cité I, IX, 53); a Cicerón, para quien «un homme ne doit jamais servir une femme, car ce serait s'avilir que de se mettre au service de moins noble que soi» (Cité, I, IX, 55); o a Catón de Útica, que opinaba que «si le monde avait été créé sans femme, nous fréquenterions les dieux» (Cité: I, IX, 56).

Ahora bien, si hay una figura que Christine de Pizan pone en cuestión es la de Jean de Meun, autor de la segunda parte del Roman de la Rose, que goza en aquel entonces de una reputación similar a la de los autores latinos, como recoge la edición de La Cité de Andrea Valentini (2014: 109). Christine valora el texto traído a colación por Dama Razón en los primeros momentos del diálogo (Cité: I, II, 39) y se enfrenta a las reglas literarias, sociales y morales de la época, abriendo la primera discusión histórica sobre el valor estético y moral de un texto literario (Greene, 2007: 297). La escritora asume en primera persona el riesgo de ser acusada por los defensores de los valores hegemónicos misóginos. Lo hace mediante un intercambio de escritos personales y cartas con defensores de Jean de Meun que llegarán hasta nuestros días, gracias a ella, y que conoceremos bajo la denominación de «Debate sobre el $R o$ man de la Rose».

Es cierto que en su edición del Livre des epistres du debat sus le Rommant de la Rose, Andrea Valentini aclara las diferencias entre su edición y la anterior de Érick Hicks (1977) y niega que en los manuscritos originales existiera un «debate» propiamente dicho, como sostiene Hicks (2014: 9) en la suya. Ahora bien, los textos, supervisados por la propia Christine de Pizan, dan cuenta de una controversia que le proporcionó defensores de su causa y el desprecio de no pocos adversarios, como Pierre Col y Jean de Montreuil ${ }^{9}$, quienes le negaron incluso el derecho a intervenir directamente en la polémica (por lo tanto, el derecho a la palabra) por el hecho de ser una mujer. Sea como fuere, Christine de Pizan aprovechó La Cité para legitimar su posición como mujer de letras, consolidada como autora y como pensadora social gracias a las palabras de Dama Rectitud: «Ma chère enfant, je ne sais plus quoi te répondre,

\footnotetext{
${ }^{9}$ Atacada por las difamaciones de quienes no aceptan que una mujer pueda cuestionar a las autoridades culturales y releer los textos legitimados, la escritora será comparada por Jean de Montreuil a «la courtisane grecque Leuntion, qui, ainsi que nous la rappelle Cicéron, osa écrire contre le grand philosophe Théophrastre», como señala Hicks (1977: 154, vv. 9-11, 43) en su edición del Débat. Montreuil nunca llegó a reconocer públicamente la autoridad de Christine de Pizan y se negó a dirigirse directamente a ella por el hecho de ser una mujer. En cualquier caso, a ella se debe el primer debate literario que tiene lugar en Francia.
} 
car tu les as toi-même suffisament réfutées dans ton Épître au Dieu d'amour et tes Épîtres sur le Roman de la Roser ${ }^{10}$.

\section{La conciencia de una identidad femenina en un «ser de mujer»}

La investigación feminista ha cumplido expectativas importantes, como la de hacer visible la producción literaria de las mujeres y su lugar en la cultura común (Marini, 1990: 56). Es, precisamente, la perspectiva feminista la que nos permite resaltar el deseo de afirmación femenina de Christine de Pizan que, en su defensa de las mujeres, ha sido calificada como feminista de "ola cero" (edición de La Cité de Valentini, 2014: 134-138), precursora feminista o incluso feminista ante litteram (Laurenzi, 2009). Aun cuando como hemos señalado al inicio de este trabajo, la expresión «sexo femenino» está lejos de poseer en una obra del siglo XV un valor generalizante para remitir a todas las mujeres, Christine de Pizan contraviene el discurso dominante de las convenciones medievales de representación y se hace transgresora y provocadora al mostrar un yo-mujer que comienza a contarse y a reclamar autoridad y un espacio propio en el ámbito sociocultural. Por ello mismo es posible hablar en su caso de una actitud feminista fundada en una doble conciencia: la de haber nacido en un cuerpo de mujer y la lucidez de reconocer la utilización política y ética masculina para justificar la subordinación social de las mujeres (Rivera-Garretas, 1994: 27), que obstaculiza, y en muchos casos impide, el desarrollo intelectual, social y cultural de las mujeres en la Baja Edad Media.

La construcción discursiva sobre la subjetividad femenina en La Cité des Dames se centra en la experiencia de un cuerpo sexuado en femenino, que está en el origen de todo tipo de restricciones entre las mujeres medievales: «je me mis à réfléchir sur ma conduite, moi qui suis née femme» (I, I, 36); «je me désespérais que Dieu m'ait fait naître dans un corps féminin» (I, I, 38), etc. Estas premisas retóricas juegan un papel sustancial como punto de arranque de un compromiso personal y artístico que acompañará a Christine de Pizan a lo largo de su viaje vital e intelectual, como ella misma afirma en el Épître dédicatoire à Isabeau de Bavière:

[...] pourrés entendre la diligence, desir et voulenté ou ma ma petite puissance s'estent a soustenir par deffences veritables contre aucunes oppinions a honnesteté contraires, et aussi l'onneur et louange des femmes, la quelle plusieurs clercs et autres se sont efforciez par leurs dictiez d'amenuisier, qui n'est chose loisible a souffrir ne soustenir (Debat: [4b], p. 150).

Las epístolas con motivo del debate anteriormente mencionado sobre el Roman de la Rose, «qui jouit d'un plus grand crédit en raison de l'autorité plus grande de

\footnotetext{
${ }^{10}$ Tal y como recogen las ediciones de Éric Hicks (1977) y de Andrea Valentini (2014), fue la propia Christine de Pizan quien se encargó de resumir el debate y de hacerlo público, convirtiéndolo de este modo en una de sus obras literarias, bajo el título Epistres du debat sus le Rommant de la Rose.
} 
son auteur» (Cité: I, II, 39), ofrecen una información palmaria sobre la propia experiencia («l'expérience de ton propre corps»; «les femmes peuvent savoir par expérience que certaines choses dans ce livre [Du Secret des femmes] n'ont aucune réalité», Cité: I, IX, 53). Además, ponen de manifiesto la conciencia sexuada y solidaria de Christine de Pizan con el resto de las mujeres. Su «Ciudad nueva y eterna» de las Damas está construida a imagen de la nueva Ciudad de Jerusalén. Pero contrariamente a lo que sucede en la Jerusalén ideal, cuyas puertas permanecen siempre abiertas ( Sus puertas nunca serán cerradas de día, pues allí no habrá noche», Apocalipsis: 21, 25), la Ciudad de las Damas es de naturaleza defensiva porque, según explica Dama Razón a la protagonista, se construye como una alegoría del cuerpo femenino, y, por lo tanto, debe tener sólidas defensas para repeler los ataques:

Ainsi, ma chère enfant, c'est à toi entre toutes les femmes que revient le privilège de faire et de bâtir la Cité des Dames. Et, pour accomplir cette oeuvre, tu prendras et puiseras l'eau vive en nous trois, comme en une source claire; nous te livrerons des matériaux plus durs et plus résistants que n'est le marbre massif avant d'être cimenté [...] afin que tu fasses de solides fondations, que tu lèves tout autour les grands murs hauts et épais avec leurs hautes tours larges et grandes, les bastions avec leurs fossés. Les bastides artificielles et naturelles, ainsi qu'il convient à une place bien défendue (Cité: I, IV, 43-44).

Según María Milagros Rivera Garreta (2003: 94), esta Ciudad, ideada a imagen de la polis griega y en parámetros de la religión cristiana, es una comunidad política original de doble inspiración, clásica y europea, espiritual y laica que, combinada con la «originalidad intelectual» de Christine de Pizan, acrecienta la posibilidad de libertad que se ofrece a las mujeres en la vida monástica cristiana. A la particular utilización de tres figuras femeninas laicas para dirigir la construcción es innovadora, se une, por tanto, esa idea de "comunidad política»; se une, igualmente, la puesta en valor que realizan Colette T. Hall y Derk Visser (1997: 32) sobre el desarrollo de un nuevo mito basado en la idea de una comunidad femenina capaz de cruzar los siglos, «invencible y eterna», para «inspirar y sustentar las utopías de numerosas escritoras de las últimas décadas, Monique Wittig, Marie Cardinal, Michèle Sarde o Charlotte Perkins Gilman».

Christine de Pizan comparte con todo el sexo femenino la terrible carga de ser objeto de acusaciones milenarias («je ne pouvais ni comprendre ni admettre le bienfondé de leur jugement sur la nature et la conduite des femmes», Cité: I, I, 36) y protagoniza el primer intento femenino de revisión de los mitos dañinos que confinaban a las mujeres en una serie de estereotipos inquebrantables (Hall y Visser, 1997: 21), cosificando sus cuerpos y desproveyéndolas de humanidad. La Cité recoge esta doxa y la readapta «en un nuevo y poderoso contexto feminista» (Brownlee, 2018: 256). Gracias al poder narrativo de las preguntas-pretexto que va formulando a las Damas, 
Christine de Pizan re-construye un sujeto femenino otro respecto del que produce el discurso normativo. El relato de La Cité se convierte así en relato de legitimación de la palabra/escritura de la autora y, por tanto, de la palabra/escritura de las mujeres.

Christine de Pizan sabe que el ingreso en el Olimpo de las letras es más exigente con las escritoras que con los escritores. Ellos pueden extraer sus modelos de entre el amplio repertorio de opciones consolidadas a lo largo de una «dilatada tradición patrilineal» (Østenstad, 2013: 115), pero su Christine se duele de la ausencia de modelos sobre los que forjar su identidad como enunciadora del relato: «Philosophes, poètes et moralistes -et la liste en serait bien longue-, tous semblent parler d'une même voix pour conclure que la femme est foncièrement mauvaise et portée au vice» (Cité: I, I, 36).

La autora reclama el derecho a la palabra desde una conciencia de la diferencia sexual que separa a hombres y mujeres. Para llevar adelante este propósito, se ampara una vez más en el obligado topos medieval de la humilitas de la protagonista, que se refiere a sí misma como «simple, indigne de poser [des] questions aux Dames», dueña de un cuerpo débil de mujer o pobre de espíritu, a quien «Dieu a accordé la parole [...] pour mieux servir sa gloire» (Cité: I, X, 61). Son numerosas las expresiones que hacen referencia a esta lectura negativa del cuerpo-experiencia para legitimar su escritura, acatando así los principios retóricos obligados que están en el origen de las fórmulas de captatio benevolentiae para la transmisión de la palabra escrita. Sin embargo, este tipo de alusiones a la naturaleza para excusar una supuesta imperfección del texto y preparar un pacto de lectura que predisponga a una interpretación favorable del público, son comunes a muchas escritoras a lo largo de siglos. De hecho, constituye una práctica específicamente femenina que abunda sobre todo en prólogos, dedicatorias y demás elementos peritextuales autorales: el ser mujer forma parte del elenco de razones irracionales por las que las escritoras necesitan excusarse para hacer pública su palabra sabia y evaluadora.

Deseosa de la gloria que le es negada a las mujeres, en un siglo en el que tanto el acceso al conocimiento como las posibilidades intelectuales y artísticas de las mujeres son casi inexistentes, Christine de Pizan atribuye a su condición de mujer la causa fundamental de los problemas que encuentra para que su palabra -literaria y no literaria- siente autoridad (Cabré i Pairet, 1993: 42) y no duda en rebatir los discursos patriarcales gracias a un argumento extraordinariamente moderno sobre las condiciones de la educación de las niñas:

Si c'était la coutume d'envoyer les petites filles à l'école et de leur enseigner méthodiquement les sciences, comme on le fait pour les garçons, elles apprendraient et comprendraient les difficultés de tous les arts et de toutes les sciences aussi bien qu'eux (Cité, I, XXVII, 91-92). 
El último capítulo de La Cité des Dames propone un giro enunciativo: concluido el diálogo con las tres damas, una vez finalizada la Ciudad, Christine interpela abiertamente a un público expresamente femenino, a las lectoras, sus "hermanas», mujeres de toda condición, del pasado, del presente y del futuro, para que se mantengan unidas y vigilantes ante las agresiones motivadas por su condición femenina:

Enfin, vous toutes, mes dames, femmes de grande, de moyenne ou d'humble condition, avant toute chose restez sur vos gardes et soyez vigilantes pour vous défendre contre les ennemis de votre honneur et de votre vertu. [...] Daignez, mes très vénérées dames, accroître et multiplier les habitantes de notre Cité (Cité: III, XIX, 275-278).

\section{Conclusiones}

En La Cité des Dames, tanto la escritura en primera persona, que revela una estrecha relación entre el lenguaje y el cuerpo, como la intervención de las tres damas y el desfile de la galería de figuras femeninas, cobran su sentido pleno en una percepción colectiva del "ser mujer» que es considerada por una parte importante de la crítica feminista como una perspectiva de género primigenia. La escritura del yo sexuado tiene la particularidad de presentar el texto atravesado por una subjetividad femenina que desvela el proyecto de la autora de escribirse a sí misma. Por otra parte, el ethos discursivo de Pizan como narradora-autora se convierte en una identidad colectiva entre un yo, que se refiere al auctor, y un nosotras que acaba arrastrando a todas las mujeres en un ejercicio de sororidad manifiesta.

Christine de Pizan mueve los hilos narrativos en torno a una narradorapersonaje que lleva su mismo nombre, se denomina a sí misma mujer y se sirve de técnicas y estrategias literarias, claves culturales, históricas y retóricas, así como de un régimen de mediación femenino para construir un nuevo orden social ideal: su ginecotopía. Se trata de una visión del mundo que parte de una experiencia sexuada en femenino (otra, no hegemónica) en el conjunto de los textos medievales e instaura un espacio para el debate sobre las condiciones de las mujeres en la Edad Media. Para ello, Christine de Pizan construye su yo como «sujeto consciente» a través de una escritura autodiegética y reflexiva que la faculta para exponer muchas de las objeciones sociales y culturales formuladas contra la autonomía de las mujeres como sujetos de pensamiento y de acción, rebatiendo de este modo construcciones degradantes de lo femenino.

Este universo simbólico que instituye Le Livre de la Cité des Dames es posible gracias al juego intertextual e intercultural que asegura la legibilidad de la obra. Christine de Pizan desarrolla una escenografía específica sobre la que cimienta la auctoritas de su escritura y de su relato; la construye valiéndose de la tradición clásica y del ámbito religioso, dos mediaciones incontestables en la época, pero siempre en femenino. Dicha escenografía reposa sobre escenas enunciativas ya validadas, como la de la 
Anunciación de Gabriel a María para hacerle saber su próxima maternidad, que Christine-autora reescribe como aparición-anunciación de las Tres Virtudes a la protagonista, Christine-personaje, con el fin de encomendarle la construcción de una Ciudad nueva y eterna para mujeres virtuosas, lo cual, a su vez, da pie a la escritura del Livre de la Cité des Dames. Todo ello, en un espacio propio, en un estudio, lugar tradicionalmente masculino, que se reconstruye discursivamente para reconvertirse en lugar de conocimiento y acción exclusivamente femenino.

El pacto de lectura que propone Christine de Pizan a su público lector conlleva también una instancia lectora femenina que se siente concernida por los problemas que inquietan a la autora. De este modo, el relato prevé la lectura marcada de una lectora que, bien desde su propia experiencia personal o bien a partir de la lectura del texto revelador, sospecha de la falsedad de las opiniones vertidas contra su sexo: todas las mujeres que aparecen en La Cité des Dames ponen de manifiesto que los únicos obstáculos que les impiden ir más allá de los límites de sus ocupaciones no provienen de sus cuerpos, sino del significado de dichos cuerpos de mujer en el discurso hegemónico de su tiempo.

Christine de Pizan, mujer y laica, se posiciona de este modo en una perspectiva sorprendentemente moderna a propósito del carácter construido de las identidades culturales y promueve, más allá de los tópicos medievales, una concepción de la feminidad que tiene en cuenta el carácter construido del discurso sobre el cuerpo y sobre el sexo. La interpelación final al público femenino, lectoras de su obra, no ofrece lugar a dudas: todas las mujeres de «alta, media o baja condición» tienen que estar siempre vigilantes para defender su valía. La conclusión del relato coincide también con la finalización de la construcción de la Ciudad de las Damas, cuyo éxito como proyecto social para las mujeres conllevará a su vez la entrada de la obra literaria de Christine de Pizan en el Olimpo de la escritura y, por ende, el entroncamiento de su autora como escritora y como mujer de letras y de ciencia, siguiendo un movimiento circular que se completa y se auto-justifica.

\section{REFERENCIAS BIBLIOGRÁFICAS}

AmOSsY, Ruth (2010): La présentation de soi. Ethos et identité verbale. París, Armand Colin. BARD, Christine (2018). «Insaisissable féminisme». Cités, 73/1, 19-28.

BLANCHARD, Joël (1990). "Christine de Pizan: tradition, expérience et traduction». Romania, 111/441-442, 200-235.

BLUMENFELD-KOSINSKI, Renate (2001): "Christine de Pizan et l'(auto)biographie féminine». Mélanges de l'École française de Rome. Italie et Méditerranée, 113/1 (Alle origini della biografia femminile: dal modello alla storia), 17-28. 
BRATU, Cristian (2019): "Je, auteur de ce livre»: L'affirmation de soi chez les historiens, de l'Antiquité à la fin du Moyen Âge. Leiden y Boston, Brill.

BROWNLEE, Kevin (2000): «Le projet "autobiographique” de Christine de Pizan», in Éric Hicks, Diego González \& Philippe Simon (ed.), Au champs des escriptures, III Colloque international sur Christine de Pizan. Lausanne, 18-22 juillet 1998. París, Honoré Champion, 5-23.

BROWNLEE, Kevin (2018): «Transforms Boccaccio: Gendered Authorship in De mulieribus claris and the Cité des dames», in Olivia Holmes \& Dana E. Stewart (ed.), Reconsidering Boccaccio: Medieval Contexts and Global Intertexts. Toronto, Toronto University Press, 246-259.

CABRÉ I PAIRET, Montserrat (1993): «La ciencia de las mujeres en la Edad Media. Reflexiones sobre la autoría femenina», in Cristina Segura (ed.), La voz del silencio, II: Historia de las mujeres: compromiso y método. Madrid, Al-Mudayna, 41-74.

CARAFFI, Patrizia (1998): «Autorità femminine e Ri-scrittura della tradizione: La Cité des Dames di Christine de Pizan», in Carlo Donà \& Mario Mancini (ed.), Tradizione Letteraria, Iniziazione, Genealogia. Milán, Luni editrice, 63-81.

CATELLI, Nora (1991): El espacio autobiográfico. Barcelona, Lumen.

CERQUiglini, Jacqueline (1993): La Couleur de la mélancolie. La fréquentation des livres au XIV siècle. París, Hatier.

CERQUiglini-TOUleT Jacqueline (1994): «Fondements et fondations de l'écriture chez Christine de Pizan. Scènes de lecture et Scènes d'incarnation", in Margarete Zimmermann \& Dina De Rentiis (ed.), The City of Scholars. New Approaches to Christine de Pizan. Berlín / Nueva York, Walter de Gruyter, 79-96.

CERQUiglini-TOUleT Jacqueline (2006): «L'inspiration des poètes lyriques à la fin du Moyen Âge: le cas de Christine de Pizan», in Claire Kappler \& Roger Grozelier (dir.), L'Inspiration. Le Souffle createur dans les arts, litteratures et mystiques du Moyen Âge européen et proche-oriental. París / Budapest / Kinshasa, L'Harmattan («Bibliothèque Kubaba»), 291-302.

CHRISTINE DE PISAN (1990). La ciutat de les dames. Introducción y traducción de Mercè Otero i Vidal. Barcelona, Edicions de l'Eixample.

Christine de Pizan (1996). La Cité des Dames. Edición de Thérèse Moreau y Éric Hicks. París, Stock/Moyen Âge.

Christine De PiZAN (2000). Le livre du Chemin de Longue étude. Edición de Andrea Tarnowski. París, Librairie générale française.

Christine de Pizan (2001): Le livre de l'advision Cristine. Edición de Christine Reno y Liliane Dulac. París, Honoré Champion.

CHRISTINE DE PIZAN (2014). Le livre des epistres du debat sus le Rommant de la Rose. Edición de Andrea Valentini. París, Classiques Garnier.

Christine de Pizan, Jean Gerson, Jean de Montreuil, Gontier \& Pierre Col (1977): Le débat sur Le Roman de la Rose. Edición de Éric Hicks. París, Honoré Champion. 
DELORMAS, Pascale (2015): «Écriture de soi et régime de singularisation dans le champs littéraire», in Johannes Angermuller \& Gilles Philippe (ed.). Analyse du discours et dispositifs d'énonciation. Autour des travaux de Dominique Maingueneau. Limoges, Lambert-Lucas, 177-186.

ECO, Umberto (1979): Lector in fabula. La cooperazione interpretativa nei testi narrative. Milán, Tascabili.

HALL, Colette T. \& Derk VISSER (1997): «La Réécriture d'une métaphore utopique: les sources bibliques de Christine de Pizan dans La Cité des damess, in Joëlle Cauville et Metka Zupančič (dir.), Réécriture des mythes: l'utopie au féminin, Amsterdam-Atlanta, GA, Rodopi, 21-34.

HEIDMANN, Ute (2011): «Expérimentation générique et dialogisme intertextuel: Perrault, La Fontaine, Apulée, Straparola, Basile». Féeries, 8, 45-69.

HUBIER, Sébastien (2003): Littératures intimes. Les expressions du moi, de l'autobiographie à l'autofiction. París, Armand Colin.

IBEAS VUelTA, Nieves (1990): «Christine de Pisan: una actitud crítica frente a las lecturas misóginas de la época», in $\mathrm{M}^{a}$ Eugenia Lacarra et al., Estudios históricos y literarios sobre la mujer medieval. Málaga, Diputación de Málaga, 71-94.

IBEAS VUELTA, Nieves \& Ma Ángeles MiLlán MuNíí (1998): «¿Por qué Naturaleza habría de avergonzarse? A propósito de La Cité des Dames de Christine de Pizan», in Àngels Carabí y Marta Segarra (ed.), Belleza escrita en femenino. Barcelona, Universitat de Barcelona, Centre Dona i Literatura, 69-78.

LABARGE, Margaret Wade (1986): A small sound of the trumpet: women in medieval life. Boston, Beacon Press.

LAURENZI, Elena (2009): «Christine de Pizan: ¿una feminista ante litteram?». Lectora, 15, 301-314.

LE GOFF, Jacques (1996): Saint Louis. París, Gallimard.

LOOZE, Laurence de (1997): Pseudoautobiography in the Fourteenth Century. Gainesville, University Press of Florida.

Maingueneau, Dominique (2004): Le discours littéraire. Paratopie et scène d'énonciation. París, Armand Colin.

MARINI, Marcelle (1990): «D'une création minoritaire à une création universelle», Savoir et différence de sexes. Les Cahiers du GRIF, 45, 51-65.

MEIZOZ, Jerôme (2007): Postures littéraires. Mises en scène modernes de l'auteur. Essai. Ginebra, Slatkine.

MUCCHIELli, Roger (1960): Le mythe de la Cité idéale. Brione, Gérard Monfort éditeur.

Oberhuber, Andrea (2013): «Dans le corps du texte». Tangence. Polygraphies du corps dans le roman de femme contemporain, 103, 5-19.

ØSTENSTAD, Inger (2013): «Se dire écrivaine : l'aspect sexuel de l'énonciation littéraire», in Pascale Delormas, Dominique Maingueneau \& Inger Østenstad (dir.), Se dire écrivain. Pratiques discursives de la mise en scène de soi. París, Lambert-Lucas, 113-126. 
Paul, Jacques (1998): Histoire intellectuelle de l'Occident médiéval. París, Armand Colin.

PlanTÉ, Christine (1997): «La sospecha del género», in Nieves Ibeas Vuelta \& María Ángeles Millán Muñío (ed.). La conjura del olvido: escritura y feminismo. Barcelona, Icaria Editorial, 75-89.

Ribemont, Bernard (2014): «Christine de Pizan, la justice et le droit». Le Moyen Âge, 118, 129-168.

Rivera Garretas, María Milagros (1994): Nombrar el mundo en femenino. Pensamiento de las mujeres y teoría feminista. Barcelona, Icaria.

Rivera GarReTAS, María Milagros (2003): «La Querelle des femmes nella Città delle Dame», in Patrizia Caraffi (ed.), Christine de Pizan. Une città per sé. Roma, Carocci, 87-97.

SCHIBANOFF, Susan (1983): «Early Women Writers: In-Scribing, or Reading The Fine Print». Women's Studies Int. Forum, 6/5, 475-489.

SLERCA, Anne (1995): «Dante, Boccace, et le Livre de la Cité des dames de Christine de Pizan", in Liliane Dulac et Bernard Ribémont (dir.), Une femme de Lettres au Moyen Âge. Études autour de Christine de Pizan. Orleans, Paradigme, 221-230.

SOLETI, Maria Alessandra (2015): Mediatrici di sapienza. Il riflesso della tradizioni profetica e femminile in Christine de Pizan. Nápoles-Salerno, Orthotes Editrice.

Verger, Jacques (1998): Les gens de savoir dans l'Europe de la fin du Moyen Âge. París, PUF.

WALTERS, Lori J. (2018): «Reading Like a Frenchwoman: Christine de Pizan's Treatment of Boccaccio's Johanna I and Andrea, Gendered Authorship De mulieribus claris and the Cité des dames», in Olivia Holmes \&y Dana E. Stewart (ed.). Reconsidering Boccaccio: Medieval Contexts and Global Intertexts. Toronto, Toronto University Press, 260-304.

ZIMMERMANN, Margarete (1999): "Querelle des femmes, querelle du livre», in Dominique de Courcelles \& Carmen Val Juliàn (dir.), Des femmes \& des livres: France et Espagne, $X I V^{e}-X V I I^{e}$ siècle. París, Honoré Champion, 79-94.

ZuMTHOR, Paul (1975): Langue, texte, énigme. París, Seuil. 